$5^{\text {th }}$ Edition, July 2006.

5. Urbańska K, Żelazko A, Domagalska

J, Nowak P (2016). Comparison of exposure to stress and analysis of ways of coping with stress among freight transport and public transport drivers. Med Pr. 2016;67(4):455-66.
6. Useche SA, Ortiz VG, Cendales BE (2017). Stress-related psychosocial factors at work, fatigue, and risky driving behavior in bus rapid transport (BRT) drivers. Accid Anal Prev. 2017 Jul;104:106-114.

\title{
ĐÁNH GIÁ GÁNH NĂNG CHĂM SÓC NGƯỜI BỆNH ĐộT QUỴ NÃO TAI NHÀ CỦA NGƯỜI CHĂM SÓC CHÍNH
}

\author{
Khúc Huyền Trang*, Võ Hồng Khôi*, \\ Nguyễn Thị Hồng Anh**, Nguyễn Ngọc Hòa***

\section{ON STROKE PATIENTS}

\section{TÓM TẮT}

Đặt vấn đề: Gánh nặng chăm sóc người bệnh sau đột quy ngày càng được công nhận là mối quan tâm đáng kể. Tại gia đình, người chăm sóc có vai trò quan trọng trong việc giúp đỡ người bệnh đột quy cả về thể chất lẫn tinh thần, tuy nhiên vai trò này có thể dẫn đến gánh nă̆ng cho người chăm sóc. Muc tiêu: Đánh giá gánh nặng chăm sóc người bệnh đột quy não tại nhà của người chăm sóc chính. Phương pháp nghiên cứu: Nghiên cứu cắt ngang, thực hiên phỏng vấn với 113 người chăm sóc khi đưa người bệnh đến tái khám taii Khoa Thần Kinh Bênh Viện Bach Mai từ tháng 12/2020 tới tháng 8/2021 dựa trên thang điểm về gánh nă̆ng chăm sóc của Zarit (Zarit Caregiver Burden Interview - ZBI). Kết quả: Người chăm sóc đa số là ban đời và con cái $(49,6 \%$ và $48,7 \%)$, là nữ giới $(64,6 \%)$, độ tuổi từ 40-60 (57,5\%), đã kết hôn $(93 \%)$, có trình đô học vấn từ cấp 3 trở lên $(62,8 \%)$ và chủ yếu là lao động chân tay $(55,7 \%)$. Điểm gánh nă̆ng ZBI trung bình là $22,88 \pm 9,4$. Điểm ZBI từ $0-$ 20 (không có gánh nặng): 44,2\%, từ 2-40 (gánh nặng vừa phải): $50,5 \%$, từ 41- 60 (gánh năng trung bình): 5,3\%. Gánh nặng chăm sóc theo một số đặc điểm của người chăm sóc: giới tính: $p=0,63$, tình trang hôn nhân: $p=0,43$, trình độ học vấn: $p=0,06$. Kết luận: Gánh nặng chăm sóc nằm trong khoảng không có gánh năng $(44,2 \%)$ cho đến gánh năng ở mức đồ vừa phải và trung bình $(55,8 \%)$, không có gánh nặng ở mức nghiêm trong. Gánh năng chăm sóc trung bình trên toàn bộ đối tượng nghiên cứu được đánh giá ở mức độ thấp. Sự khác biệt không có ý nghĩa thống kê về gánh nặng chăm sóc giữa người chăm sóc là nam hay nữ, tình trạng hôn nhân hay trình độ học vấn.

Tứ khóa: Gánh nặng chăm sóc, người chăm sóc chính, đột quy, ZBI.

\section{SUMMARY}

\section{ASSESSEMENT OF HOME CARING BURDEN}

*Bênh viện Bạch Mai

**Trướng Dai hoc Phenikaa

***Bênh viền Hữu nghi Đa khoa Nghê An

Chịu trách nhiệm chính: Khúc Huyền Trang

Email: khuchuyentrang311@gmail.com

Ngày nhận bài: 14.6.2021

Ngày phản biên khoa hoc: 9.8.2021

Ngày duyệt bài: 16.8.2021
Background: The burden of caring for patients after stroke is increasingly recognized as a significant concern. In the family, caregivers play an important role in support to stroke patients both physically and emotionally, but this role can lead to increased caregiver burden. Objective: To assess the caring burden of primary caregiver of stroke patients at home. Methods: A cross-sectional study, interviewing 113 caregivers of stroke patients at the Neurology Center of Bach Mai Hospital from December 2020 to August 2021 based on the scale "Zarit Caregiver Burden Interview - ZBI". Results: The majority of caregivers were patient's spouses and children $(49.6 \%$ and $48.7 \%)$, female $(64.6 \%)$, aged $40-60(57.5 \%)$, got married $(93 \%)$, have an education level from high school or higher $(62.8 \%)$, and manual labor $(55.7 \%)$. The mean ZBI score was $22.88 \pm 9.4$. The percentage of ZBI score from 0 to 20 (no burden), from 21 to 40 (mild to moderate burden) and from 41 to 60 (moderate to severe burden) was $44.2 \%, 50.5 \%$, and $5.3 \%$, respectively. There are no significant diffirence among gender $(p=0,63)$, marital status $(p=0,43)$ and educational background ( $p=0,06$ ) on ZBI score. Conclusion: $44.2 \%$ of caregivers have no burden, the remaining $55.8 \%$ have mild to moderate and moderate to severe burden of care, no severe burden was recored. There was no difference in burden of care among gender, marital status or education background.

Keywords: caring burden, primary caregiver stroke, ZBI

\section{I. ĐĂT VẤN ĐỀ}

Với sự tiến bộ của y học, tại những đơn vị đột quy, người bênh được chăm sóc và điều trị theo hình thức đa khoa phối hợp giúp khả năng sống sót cao hơn. Ngoài ra, can thiệp sớm vào quá trình phục hồi chức năng giúp giảm thiểu tình trạng tàn tật nặng, góp phân giúp người bệnh được ra viện và chăm sóc tại nhà.

Người bệnh sống sót sau đột quy thường để lại di chứng với nhiêu mức độ khác nhau, họ phải phụ thuộc vào gia đình để được chăm sóc trong thời gian dài. Người chăm sóc trong gia đình có vai trò quan trọng trong việc giúp đõ 
người bênh cả về thể chất lẫn tinh thần, hậu quả có thể dẫn đến gánh nặng cho người chăm sóc.

Trên thế giới đã có nhiều nghiên cứu về gánh nặng chăm sóc người bệnh đột quỵ tại nhà [1] [2] [3], tuy nhiên gánh nặng của người chăm sóc có thể được nhìn nhận khác nhau, tùy thuộc vào bối cảnh kinh tế - xã hội và nền văn hóa mà họ sống. Đó là lí do đề tài nghiên cứu này được thực hiện với mục tiêu: Mô tả thực trạng gánh nặng chăm sóc người bệnh đột quy não tại nhà của người chăm sóc chính.

\section{II. ĐỐI TƯƠNGG VÀ PHƯƠNG PHÁP NGHIÊN CỨU}

2.1. Đối tượng: Gồm 113 người chăm sóc trực tiếp người bệnh đột quy đến khám tại Trung tâm Thần Kinh - Bệnh viện Bạch Mai trong thời gian từ tháng 12/2020 tới tháng 8/2021

2.2. Thiết kế nghiên cứu: Nghiên cứu mô tả cắt ngang.

2.3. Tiêu chuẩn lựa chọn. Là người chăm sóc chính của người bệnh đột quy. não tại gia đình.

\subsection{Tiêu chuẩn loại trừ:}

- Người chăm sóc chính không thể tiếp nhận và trả lời được các câu hỏi.

- Người được chăm sóc có kèm chẩn đoán các bệnh lí khác giai đoạn tiến triển (ung thư, alzheimer, parkinson, tâm thần)

2.5. Cỡ mẫu: thuận tiện

2.6. Kỹ thuật và công cư nghiên cứu: Sử dụng kỹ thuật phỏng vấn trực tiếp.

Công cụ nghiên cứu là bộ câu hỏi gồm hai phần: Phần $A$ : đặc điểm chung. Phần $B$ : câu hỏi điều tra gánh nặng chăm sóc dựa vào thang điểm ZBI.

Thang điểm ZBI gồm 22 câu hỏi. Câu trả lời cho mỗi câu hỏi dựa trên 5 mức độ (Likert scale với $0=$ không bao giờ, $1=$ hiếm khi, $2=$ thỉnh thoảng, 3 = khá thường xuyên, 4 = luôn luôn). Tổng điểm nằm trong khoảng từ 0 điểm đến 88 điểm với các mức: không có tương ứng 0 đến 20 điểm, gánh nặng vừa phải tương ứng với 21 đến 40 điểm, gánh nặng trung bình tương ứng với 41 đến 60 điểm và gánh nặng nghiêm trọng tương ứng với 61 đến 88 điểm. Đây là bộ công cụ thiết kế bao phủ được nhiều khía cạnh và được sử dụng nhiêu nhất cho mục đích đánh giá về gánh nặng của người chăm sóc. Bộ công cụ này đã được nhiều quốc gia sử dụng như Brazil [1], Iran [2], Trung Quốc [3], Ấn Độ [4] hay Hàn Quốc [5]. Tại Việt Nam, thang điểm này đã được nhóm nghiên cứu của Nguyễn Bích Ngọc (2013) dịch sang tiếng Việt, đánh giá thử và biên tập để đảm bảo các câu hỏi rõ ràng, dễ hiểu, dễ trả lời [6].

2.5. Xử lý và phân tích số liệu. Số liệu được phân tích bằng phần mềm thống kê SPSS 20

2.6. Đạo đức nghiên cứu. Đề cương nghiên cứu đã được thông qua hội đồng đạo đức của trường Đại học điều dưỡng Nam Định. Đối tượng nghiên cứu được cung cấp các thông tin liên quan đến nghiên cứu. Họ tham gia vào nghiên cứu là tự nguyện và có quyền từ chối. Tất cả những thông tin được cung cấp sẽ được giữ bí mật.

\section{KẾT QUẢ NGHIÊN CỨU}

3.1. Đăc điểm của người chăm sóc Bảng 1. Đặc điểm của người chăm sóc

\begin{tabular}{|c|c|c|}
\hline $\begin{array}{l}\text { Đặc điếm của người } \\
\text { chăm sóc }\end{array}$ & $\mathbf{n}$ & $\begin{array}{l}\text { Ty̆ lế } \\
\%\end{array}$ \\
\hline Nhóm tuối : < 40 & 33 & 29,2 \\
\hline $40-60$ & 65 & 57,5 \\
\hline$>60$ & 15 & 13,3 \\
\hline Tuối trung bình & \multicolumn{2}{|c|}{$47,36 \pm 10,43$} \\
\hline Giới tính: Nữ & 73 & 64,6 \\
\hline Nam & 40 & 35,4 \\
\hline \multicolumn{3}{|l|}{ Tình trạng hôn nhân } \\
\hline Kết hôn & 105 & 93 \\
\hline Độc thân & 4 & 3,5 \\
\hline Ly dị/ Ly thân/ Góa & 4 & 3,5 \\
\hline \multicolumn{3}{|l|}{ Trình độ học vấn } \\
\hline Dưới trung học phố thông & 42 & 37,2 \\
\hline Từ trung học phố thông trở lên & 71 & 62,8 \\
\hline \multicolumn{3}{|c|}{ Nghề nghiệp của người chăm sóc } \\
\hline $\begin{array}{l}\text { Lao động chần tay (nông dân, } \\
\text { công nhân, nội trợ, tự do) }\end{array}$ & 63 & 55,7 \\
\hline $\begin{array}{c}\text { Lao đồng trí óc (viên chức, trí } \\
\text { thức, thương nhân) }\end{array}$ & 41 & 36,3 \\
\hline Hưu tri & 9 & 8 \\
\hline \multicolumn{3}{|l|}{ Mối quan hệ với người bệnh } \\
\hline Vơ/chông & 56 & 49,6 \\
\hline Con & 55 & 48,7 \\
\hline Ho hàng & 2 & 1,8 \\
\hline
\end{tabular}

Kết quả bảng 1: người chăm sóc đa số là bạn đời và con cái $(49,6 \%$ với $48,7 \%)$, là nữ giới $(64,6 \%)$, độ tuổi từ 40-60 (57,5\%), đã kết hôn $(93 \%)$, có trình độ học vấn từ cấp 3 trở lên $(62,8 \%)$ và chủ yếu là lao động chân tay $(55,7 \%)$.

\subsection{Gánh nặng chăm sóc.}

Bảng 2. Chỉ số gánh nặng chăm sóc $Z B I$

\begin{tabular}{|c|c|c|}
\hline Phân loại mức độ & $\mathbf{n}$ & Tỷ lệ \% \\
\hline $\begin{array}{c}\text { Không có gánh nặng } \\
\text { (0 đến 20 điểm) }\end{array}$ & 50 & 44,2 \\
\hline $\begin{array}{c}\text { Gánh nặng vữa phải } \\
\text { (21 đển 40 điểm) }\end{array}$ & 57 & 50,5 \\
\hline $\begin{array}{c}\text { Gánh nặng trung bình } \\
\text { (41 đến 60 điểm) }\end{array}$ & 6 & 5,3 \\
\hline $\begin{array}{c}\text { Gánh nặng nghiêm trọng } \\
\text { (61 đển 88 điểm) }\end{array}$ & 0 & 0 \\
\hline ZBI trung bình & \multicolumn{2}{|c|}{$22,88 \pm 9,4$} \\
\hline
\end{tabular}


Kết quả bảng 2: Điểm gánh nặng ZBI trung bình là $22,88 \pm 9,4$. 44,2\% người chăm sóc không có gánh nặng. 55,8 \% còn lại có gánh nă̆ng chăm sóc từ vừa phải đến từ trung bình. Không có gánh nặng ở mức nghiêm trọng.

Bảng 3. Gánh nặng chăm sóc theo một số đặc điểm của người chăm sóc

\begin{tabular}{|c|c|c|c|c|c|}
\hline \multirow{2}{*}{$\begin{array}{c}\text { Đặc điếím của } \\
\text { người chăm } \\
\text { sóc }\end{array}$} & \multirow[b]{2}{*}{$\mathbf{n}$} & \multirow{2}{*}{ Tỷ lệ } & \multicolumn{2}{|c|}{ Điếm ZBI } & \multirow[b]{2}{*}{$\mathbf{p}$} \\
\hline & & & TB & SD & \\
\hline \multicolumn{6}{|c|}{ Giới tính } \\
\hline Nữ & 73 & 64,6 & 23,19 & 9,19 & \multirow{2}{*}{0,63} \\
\hline Nam & 40 & 35,4 & 22,3 & 8,73 & \\
\hline \multicolumn{6}{|c|}{ Tình trạng hôn nhân } \\
\hline Độc thân & 4 & 3,5 & 27,5 & 4,5 & \multirow{3}{*}{0,43} \\
\hline Kết hôn & 105 & 93 & 22,56 & 9,63 & \\
\hline $\begin{array}{l}\text { Ly dị/ Ly thân/ } \\
\text { Góa }\end{array}$ & 4 & 3,5 & 26,5 & 4,12 & \\
\hline \multicolumn{6}{|c|}{ Trình độ học vấn } \\
\hline $\begin{array}{c}\text { Tiếu học, trung } \\
\text { học cơ sở }\end{array}$ & 42 & 37,2 & 26,12 & 9,33 & \multirow{4}{*}{0,0} \\
\hline $\begin{array}{l}\text { Phố thông trung } \\
\text { học }\end{array}$ & 27 & 23,9 & 22,04 & 8,77 & \\
\hline $\begin{array}{c}\text { Trung cấp, Cao } \\
\text { đằng }\end{array}$ & 20 & 17,7 & 23,15 & 10,51 & \\
\hline $\begin{array}{c}\text { Đại học, sau đại } \\
\text { học }\end{array}$ & 24 & 21,2 & 17,92 & 7,16 & \\
\hline
\end{tabular}

Kết quả bảng 3: Sự khác biệt không có ý nghĩa thống kê về gánh nặng chăm sóc giữa người chăm sóc là nam hay nữ $(p=0,63)$, tình trạng hôn nhân $(p=0,43)$, trình độ học vấn ( $p$ $=0,06$ ).

\section{BÀN LUẬN}

\section{1. Đặc điểm chung của người chăm sóc}

Tuổi và giới: Trong nghiên cứu của chúng tôi tuổi trung bình của người chăm sóc là 47,36 $\pm 10,43$, độ tuổi từ 40 - 60 là chủ yếu $(57,5 \%)$. Đặc điểm này tương đồng với một số nghiên cứu của tác giả khác như LuLu (2009) tuổi trung bình là 44,2 $\pm 12,4$ [3], Carod (2009) là 42 [1]. Có thể thấy rằng người chăm sóc người bệnh đột quy đang ở độ tuổi lao động chiếm tỉ lệ tương đối cao. Đa số người bệnh đột quy não là trên 60 tuổi [2],[4], và người chăm sóc chủ yếu là người thân trong gia đình (vợ/chồng, con) nên độ tuổi này của người chăm sóc là hoàn toàn hợp lý.

Người chăm sóc nữ chiếm đa số $64,6 \%$. Rất nhiêu các nghiên cứu đều cho thây người chăm sóc là nữ chiếm tỉ lệ khá cao: $59,3 \%$ [3]; $77 \%$ [1]. Điều này được giải thích bởi vì phụ nữ được xem là những người có sự nhạy cảm cao và sự cảm thông tốt hơn đồng thời họ cũng tạo ra được sự gắn kết các mối quan hệ thân thiết và bền chặt hơn[1],[3].
Mặc dù tỉ lệ nữ giới là cao hơn nhưng không có sự khác biệt có ý nghĩa thống kê về gánh nặng chăm sóc với $p=0,63$. Kết quả này phù hợp với nghiên cứu của tác giả Nguyễn Thành Chung (2016) [7].

Tình trạng hôn nhân, trình độ văn hóa, nghề nghiệp: Số lượng người chăm sóc đã lập gia đình lên tới $93 \%$, Kết quả này tương đồng với nghiên cứu của Kazemi (2020): 68,2\% [2] và Nguyển Thành Chung: 92,7\% [7]. Tuy nhiên gánh nặng người chăm sóc không có sự khác biệt có ý nghĩa thống kê giữa các nhóm với $\mathrm{p}=0,43$.

$62,8 \%$ người chăm sóc có trình độ từ trung học phổ thông trở lên. Trình độ văn hóa cao phản ánh nhận thức tốt hơn về bệnh tật và hiểu biết về kỹ nẳng chăm sóc cho người bệnh. Tuy vậy, kết quả nghiên cứu cũng cho thấy gánh nặng của người chăm sóc giữa các nhóm học vấn không có sự khác biệt với $p=0,06$.

Số lượng người chăm sóc là lao động chân tay chiếm tỷ lệ lớn với $55,7 \%$. Việc phải dành thời gian chăm sóc cho người nhà bị bệnh cũng ảnh hưởng rất lớn tới công việc của người chăm sóc. Một số người phải nghỉ việc, chỉ ở nhà làm công việc nhà và chăm sóc người bệnh. Nghiên cứu của Choi-Kwon nhận thấy rằng tình trạng thất nghiệp của cả người bệnh hoặc người chăm sóc là một yếu tố ảnh hưởng tiêu cực đến gánh nặng của người chăm sóc [5].

Mối quan hệ với người bệnh. $49,6 \%$ là bạn đời của người bệnh. $48,7 \%$ là con, chỉ có $1,8 \%$ là họ hàng, tỷ lệ này cao hớn so với nghiên cứu của Carod (2009) [1]. Vốn dĩ có sự khác biệt này có thể liên quan đến văn hóa phương Tây khi các viện dưỡng lão và viện dành cho người bênh mắc bênh mãn tính thường có sẵn, trách nhiệm chăm sóc trực tiếp của người thân được yêu cầu ở mức độ thấp hơn.

4.2. Mức độ gánh nă̆ng chăm sóc. Điểm ZBI trung bình 22,88 $\pm 9,4$ tương đương mức đô gánh nặng chăm sóc trung bình trên toàn bộ đối tượng nghiên cứu được đánh giá ở mức độ thấp (ZBI từ 21- 40 điểm). Kết quả này tương tự kết quả nghiên cứu của Carod-Artal (2009) (điểm trung bình ZBI là 27,2) [1] và Mandowara (2020) (điểm ZBI trung bình là 28,26 [4].

Trong nghiên cứu của chúng tôi, $55,8 \%$ người tham gia có gánh nă̆ng chăm sóc, ít hơn nhiều so với con số $90,6 \%$ của Nguyễn Thành Chung [7]. Chênh lệch này có thể được lý giải do sự khác biệt trong lựa chọn đối tượng nghiên cứu. Trong nghiên cứu của Nguyễn Thành Chung, tác giả lựa chon người bệnh sau ra viên từ 1 tuần, con số này trong nghiên cứu của 
chúng tôi là 1 tháng khi tình trạng bệnh nhân đã ổn định hơn. Điều này được phản ánh thông qua điểm Barthel trung bình của người bệnh là 88,76 $\pm 15,8$ trong đó chủ yếu là nhóm người bệnh không phụ thuộc (68 người chiếm $60,2 \%$ ), cao hơn nhiều so với 47,8 \pm 19,9 điểm trong công bố của Nguyễn Thành Chung [7].

\section{KẾT LUẦN}

44,2\% người chăm sóc không có gánh nặng. $55,8 \%$ còn lại có gánh nặng chăm sóc từ vừa phải đến từ trung bình. Không có trường hợp nào cảm thấy gánh nặng ở mức nghiêm trọng. Không có sự khác biệt về gánh nặng chăm sóc giữa người chăm sóc là nam hay nữ $(p=0,63)$, tình trạng hôn nhân $(p=0,43)$, trình độ học vấn $(p=0,06)$

\section{TÀI LIỆ THAM KHẢO}

1. Carod-Artal, F.J., et al. (2009), Burden and perceived health status among caregivers of stroke patients. Cerebrovasc Dis, 28(5) p. 472-80.

2. Kazemi, A., et al. (2020), Caregiver Burden and Coping Strategies in Caregivers of Elderly Patients with Stroke.

3. Lu, L., et al. (2009), Zarit Caregiver Burden Interview: Development, reliability and validity of the Chinese version. Psychiatry and Clinical Neurosciences, 63(6) p. 730-734.

4. Mandowara, B., et al. (2020), Burden Faced by Caregivers of Stroke Patients Who Attend Ruralbased Medical Teaching Hospital in Western India. Annals of Indian Academy of Neurology. 23(1): p. 38-43.

5. Choi-Kwon, S., et al. (2005), Factors affecting the burden on caregivers of stroke survivors in South Korea. Arch Phys Med Rehabil, 86(5) p. 1043-8.

6. Nguyễn Bích Ngọc (2013), Đánh giá gánh nặng của người chăm sóc trong bệnh alzheimer. Tạp chí Y hoc dư phòng, Tâp XXIII, số 5

7. Nguyê̂n Thành Chung (2016), Nghiên cứu gánh năng chăm sóc người bênh sau đôt quy não tai gia đình ở tỉnh Nam Đinh năm 2016. Luân văn thac sĩ điều dưỡng.

\section{KẾT QUẢ HÓA XA TRI TIỀN PHẪU UNG THƯ THỰC QUẢN 1/3 GIŨ̃A- DƯỚI GIAI ĐOẠN II, III TẠI BỆNH VIỆN TRUNG ƯƠNG QUÂN ĐộI 108}

\section{TÓM TẮT.}

Muc tiêu: Mô tả môt số đăc điểm lâm sàng, cân lâm sàng của bệnh nhân ung thư thực quản $1 / 3$ giứadưới giai đoan İI, III tai bênh viện Trung ương Quân đội 108 được hóa xạ trị tiền phẫu và đánh giá kết quả điêu trị của nhóm bệnh nhân trên. Đối tượng và phương pháp: Nghiền cứu mô tả hồi cứu kết hợp tiến cứu trên 44 bệnh nhân ung thư thực quản $1 / 3$ giữa - $1 / 3$ dưới giai đoạn II-III điều trị hóa xa trị tiên phẫu với phác đồ hóa chất Paclitaxel/Carboplatin kết hợp liều xạ trị 41,4Gy/23Fx và phâuu thuật. Kết quả: Tuổi trung bình là 55 , tỷ lệ nam là $97,7 \%$. Triệu chứng chủ yếu là nuốt nghẹn $81,8 \%$, sút cân găp ở $27 / 44$ $(61,2 \%)$, chiều dài trung bình của u là $6 \pm 0,25 \mathrm{~cm}$. Đáp ứng hoàn toàn trên cận lâm sàng tương ứng là $38,6 \%$. Đáp ứng hoàn toàn trên giải phâuu bệnh là $43,2 \%$ (pTON0). Các độc tính chủ yếu đồ 1-2 bao gồm mệt mỏi, viêm niêm mạc thực quản, hạ bạch cầu. Kết luần: hóa xa trị tiền phấu là phương pháp điều trị có hiệu quả cho ung thư thực quản $1 / 3$ giữa- dưới giai đoạn II-III với tác dụng không mong muốn có thể chẩp nhân được.

Tư khóa: Hóa xạ trị tiền phẫu, ung thư thực quản.

${ }^{1}$ Bệnh viện Trung ương quân đội 108

${ }^{2}$ Bộ môn Ung thur, Trường Đại hoc Y Hà Nội

Chịu trách nhiệm chính: Trịnh Lế Huy

Email: trinhlehuy@hmu.edu.vn

Ngày nhận bài: 16.6.2021

Ngày phản biên khoa hoc: 13.8.2021

Ngày duyệt bài: 18.8.2021
Nguyễn Thị Hà1, Trịnh Lê Huy ${ }^{2}$

\section{SUMMARY \\ RESULTS OF NEOADJUVANT CONCURRENT CHEMORADIOTHERAPY IN STAGE II-III \\ MIDDLE-LOWER THIRD ESOPHAGEAL CANCER AT 108 CENTRAL MILITARY HOSPITAL}

Objectives:To assess the treatment results of neoadjuvant chemoradiation in the middle and lower thirds, stage II, III esophageal cancer patients at the 108 Military Central Hospital. Subject and method:A retrospective and prospective descriptive study with 44 stage II-III esophageal cancer patientsunderwent preoperative, concurrent chemotherapy with paclitaxel/carboplatin and radiation with a dose of 41.4Gy/23fx followed by surgery. Results: The means age was 55 years old, the percentage of malewas $97,7 \%$. The dysphagia rate was 81,8 , weight loss was found in $27 / 44(61,2 \%)$, the mean length of tumor is $6 \pm 0.25 \mathrm{~cm}$. The subclinical complete responses were $38.6 \%$. The pathology complete response was $43.2 \%$ (PTONO) and RO resection was achieved for 41 patients (93.2\%). Side effects fatigue, esophageal mucositis, and leukopenia, most of which were in grade 1-2.Conclusions:Preoperative chemoradiation in an effective treatment for stgage IIIII esophageal cancer patients with acceptable side effects, complications, and surgical complications.

Keywords: Esophageal cancer, preoperative chemoradiotherapy. 